\title{
8. REVIEWS
}

\section{EDITORS}

Susan B. Johnson

Jana E. M iyahira-Smith

Thomas W. Overton

\section{Rings: Jewelry of Power, Love and Loyalty}

By Diana Scarisbrick, 384 pp., illus., publ. by Thames \& Hudson Ltd. [www.thamesandhudsonusa.com], London, 2007. U S\$50.00

In the course of her rich career, jewelry historian Diana Scarisbrick has written about a variety of arcane, rarefied topics ranging from tiaras and cameo carvings to Tudor and Jacobean jewel ry. In Rings, she indulges her special interest in some of the smallest yet most potent jewelry objects. The result is a scholarly tour de force told by tiny survivors that memorialize mankind's artistic sensibilities and technological advances as much as our beliefs and dreams.

By organizing her book by theme before chronology, Scarisbrick demonstrates how rings embody the spirit of the age in which they were created. She examines eight different themes: rings as signets; love, marriage, and friendship rings; devotional, apotropaic (to "ward off evil"), and ecclesiastical rings; memento mori and memorial rings; rings associated with illustrious people and great events; decorative rings; the diamond ring; and the ring as accessory.

The core source for the book's 483 illustrations, most of which are in color, is the Benjamin Zucker Family Collection, supplemented by examples from museums and other collections, both private and public. Insightful legends that underscore significant or archetypal features accompany tidy photographs and illustrations.
The content is rich in anecdote, historical footnotes, and quotations. Scarisbrick leaves no illustrative source unturned, embellishing the academic tone with portraits and oil paintings, engravings, woodcuts, old catalogues, ancient writings, inscriptions, drawings, publicity materials, and early photographs. Beyond familiar sources such as Pliny's Natural History, the author cites literature from Greco-Roman classicism to publications of bygone eras that presage the modern age, sampling Lord Byron's letters to Ladies' Monthly Museum at the turn of the 18th century and news from The Tatler a century later. The scholarly treatise is further supported by source notes for illustrations and text, a bibliography, and an excellent index.

The book ends with its shortest and least expansive chapter, devoted to rings as accessories, which primarily focuses on calendar and watch rings, as well as "poison rings" used to hide lethal substances.

While the book is not suited to casual reading, its thematic organization makes it a valuable resource for those seeking specific insight into design invention or reinvention and jewelry as a reflection of its time. The book deserves recognition beyond its must-have status as a definitive reference for jewelry historians, curators, and designers, to include all those interested in examining civilization through the looking glass of our most personal jewels-rings.

MATILDE PARENTE Libertine Indian Wells, California

\section{The Emerald Book}

By Yogi Durlabhji, Shyamala Fernandes, and Ruchi Durlabhji, Eds., 143 pp., illus., publ. on behalf of the Jaipur Jewellery Show [info@aipurjewelleryshow.org], Jaipur, India, 2007. Free [limited distribution]

The Emerald Book was created to provide insight into the world of emeral ds and the emeral d industry, and to highlight Jaipur as a trading center. As a promotional book published in conjunction with the 2006 Jai pur Jewellery Show, it has a polished, professional look: The layout is attractive, and it is lavishly illustrated and printed on high-quality glossy paper.

However, the text is organized in a way that makes it difficult, at first glance, to grasp the general content. There is no table of contents, and the book starts immediately with the chapter "Romance and Rhapsody," describing the earliest sources of emerald and showing historic pieces of emerald jewelry. It reviews the discovery of Colombian emeralds and their effect on the world market, especially on Indian royalty. Also shown are examples of emerald carvings throughout history, and important emeralds and impressive pieces of jewelry (some with Indian designs), many of which are now owned by royal European families or held in museums throughout the world.

Two brief sections cover beliefs in the magical power of emerald, especially within ancient Indian philosophies. The next section describes the 
history and evolution of the emerald trade in Jai pur. It gives the reader a good understanding of how Jaipur built its position as an emeral d center, and how its sources of supply changed over the years, with Zambia now the only important one. A very concise overview of the most important commercial emerald mines reveals some interesting facts about the current mining situation. However, a section about "The Great Jewellers" seems a bit out of place. Although much attention is paid to their general impact on the jewelry trade, only one example is given of how a jeweler was inspired to use emeralds in a piece of jewelry. In my opinion, more in-depth information about this jeweler's thought process would have made this section more interesting and appropriate.

There is little geology or gemology in this book. As a result, a discussion about the term red emerald seems sudden and out of place, since the reader must have a thorough understanding of beryl gemology to be ableto follow it.

For all those who love emeralds and jewelry, though, this book gives an interesting and honest insider's look into the emerald trade. The authors express great pride in the profession and in Jai pur's status within the industry, but they also mention smuggling, robberies, violence at emerald sources, and concerns about the many museum pieces that are meant to be shown to the public, but all too often remain locked away in vaults.

HANCO ZWAAN Netherlands Gemmological Laboratory National Museum of Natural History Naturalis Leiden, The N etherlands

\section{Jewelry Savvy: What Every Jewelry W earer Should Know}

By Cynthia A. Sliwa and Caroline Stanley, 224 pp., illus., publ. by Jewels on Jewels, Los Angeles, [www.jewel rysavvybook.com], 2007. U S\$19.99

At some point, every jeweler experi- ences the dilemma of a customer who returns an item but cannot be specific about the reason, except to say, "It just didn't look right." You try to save the sale or come up with an alternative, but in the end both of you walk away shaking your heads.

When faced with this scenario, you have to know that it is not the customer, and it is not the price points; it is the jewelry-the wrong type of jewelry for the body type, personality, and style of the wearer. The art of adornment is very nuanced, and Jewelry Savvy is a perfect book for both sides of the counter-a self-help book for the consumer and a marketing book for jewelers.

The authors are a singular collaboration of style consultant and fourthgeneration jeweler, with decades of experience between them, who bring practical advice to the choosing and wearing of jewelry. Each chapter starts with a clever quote while addressing the anatomy of choosing the right jewel. Helpful shadow boxes of "Savvy Tips" further drive home the points of the chapter.

The emphasis is on the wearer, with in-depth discussion of physical features, personality, face shapes, and specific body types-in other words, the signature style of the purchaser. The authors encourage jewelers to experiment with color, texture, necklace length, placement, and combinations of pieces.

The primer on metals, diamonds, and gemstones is presented in a conversational, jargon-free tone. Hel pful charts that sort gemstones by color, birthstone, anniversaries, and safety in the ultrasonic cleaner, as well as useful terminologies, are liberally sprinkled throughout the book. Further information on cleaning and storage, as well as traveling with jewelry and gemstones, is also included. The section on which jewelry items should be stored in a soft pouch and which ones need to be stored in a plastic bag is a good one to review with your clients.

Considering all this, the "Jewelers and Appraisals" chapter is something of a disappointment. The appraisal document example is not within industry standards, and may give a false impression of completeness. In addition, the resources chapter does not list any of the major appraisal organizations. The lack of an index is also frustrating when you try to go back to review a topic. However, the overall appeal to consumers is achieved by clear, uncomplicated text, making this book a success.

$$
\begin{array}{r}
\text { GAIL BRETT LEVINE, GG } \\
\text { National Association of } \\
\text { Jewelry Appraisers } \\
\text { Rego Park, New York }
\end{array}
$$

\section{In G old We Trust: Social Capital and Economic Change in the Italian Jewelry Towns}
By Dario Gaggio, 352 pp., publ. by
Princeton U niversity Press [press.princeton.edu], Princeton, NJ, 2007. U $\$ 39.50$

By the 1960s, despite their relatively small size and spotty-to-nonexistent goldmaking traditions, the small towns of A rezzo, Valenza Po, and Vicenza had come to dominate the Ital ian gold industry. Each town did it its own way, with Tuscany's Arezzo eventually identified with global reach and stylized manufacturing, Piedmont's Valenza Po with craftsmanship and artisanal flair, and the Veneto's Vicenza with industrialized mass production.

The way each town rapidly transformed into its ultimate brand-incarnation in the gold and jewel ry world is the subject of Dario Gaggio's In Gold We Trust. In his rigorous academic and socio-scientific treatise, the University of Michigan assistant professor of history explores each town's unique socio-cultural and economic factors and how they intertwined with politics, demography, tradition, and trust, among other factors, to spawn the specialized entrepreneurship and small-scale industrialization now recognized as synonymous with quality and style. 
Gaggio also examines the decline of Providence, Rhode Island, a city once at the core of America's industrial revolution. With varying success, the author draws paral lels and contrasts between the operative dynamics of Providence and that of the Italian towns to examine how and why Providence's jewelry industry eventually lost touch with American modernity. One might also theorize a missing link that emerged in one persona or another in the Italian towns-firebrand, visionary, or dominant leaders capable of gal vanizing industry and the workforce to better adapt to the societal, labor and demographic challenges of the times, as well as emerging competitors. It wasn't al ways pretty.

This is a high-concept book that cites the writings and polemics of historians, sociologists, political scientists, and philosophers. It is not a book for casual jewelry buffs or romanticist Italophiles. Rather than engage in simplistic arguments about northern Italian prosperity and the corruption and backwardness of the south, the author presents meticulously researched and footnoted arguments in a specialized and oftenarcane academic style more suited to an audience of serious historians and cultural anthropologists. Business school students and their professors, as well as motivated and patient readers interested in Italian culture and its rich jewelry history, may also strike gold.

MATILDE PARENTE

\section{Safety Solutions}

63 pp., illus. with DVD, publ. by MJSA Press [www.mjsa.org/info_press.php], Providence, RI, 2007. \$49.95 (\$29.95 for DVD alone)

In an increasingly fast-paced world where any assumptions as to a person's understanding of his or her trade are as reliable as winning a late-night game of poker, Safety Solutions is a resource no business can afford to do without. One might call it the $\mathrm{N}$ orth American reference manual on how to set up a jewelry manufacturing operation that minimizes hazards to employees and property, while maintaining efficiency and profitability.

There are two parts: a 56-page booklet and a 20-minute presentation on DVD, both tightly structured and complementing one another.

Besides addressing regulations pertaining to fire safety, building codes, and hazardous materials, the first section specifically introduces California Proposition 65 (intended to keep toxic substances out of consumer products) and national lead poisoning legislation. Although the information is useful, this reviewer would like to have al so seen a recommendation that fire alarms and smoke detectors be integrated with security systems, and that fire extinguishers be placed near exits.

The next section discusses the workplace programs for hazard communication. It revolves around material safety data sheets (MSDS) as well as injury and illness prevention. Section three is a selection of excerpts from Charles Lewton-Brain's Jewely Workshop Safety Report (Brain Press Ltd., Cal gary, Alberta, Canada, 1998 [www.brai npress.com]), which addresses safe practices in the studio. It takes a closer look at the numerous aspects of safety at the bench and in the casting room, and how to deal with chemicals and chemical inventories. Safety checklists and safety resources are the topics of sections four and five, respectively.

The DVD presentation shares the same objective and covers the topics with comparable emphasis. The order in which topics are presented, howev$e r$, has been somewhat adapted to the medium.

While most of the information covered in both the publication and the DVD might be shrugged off as common sense, the authors of Safety Solutions have kept the content as comprehensive as possible. But make no mistake: The focus is on the preventive aspect of safety, with little about response. You will not find first aid mentioned anywhere in the entire publication. "Is a spill kit available?" or "Is there a procedure in place for dealing with serious injuries that require medical treatment outside the facility?" are as specific as it gets on the subject of response.

Although an ounce of prevention certainly is worth more than a pound of cure, response issues should not be neglected. Thus, purchasers of this work will certainly want to ensure that all emergency numbers remain posted on all their tel ecom devices.

ROBERT ACKERMAN, GG

Gemological Institute of America Carlsbad, California

\section{OTHER BOOKS RECEVED}

Diamonds Are Waiting for You. By James R. Holland, 63 pp., illus., publ. by A Bit of Boston Books [www.bitofboston.com], Boston, MA, 2007, $\$ 12.00$. This brief booklet describes the author's trip with his family to the Crater of Diamonds State Park in Murfreesboro, Arkansas. The history of the park and its current status as a public diamond area are reviewed. Also included are tips for would-be diamond diggers. N ote that the author incorrectly refers to the site's lamproite deposits as kimberlite.

TWO

\section{Late Antique and Early Christian} Gems. By Jeffery Spier, 221 pp. with 154 black-and-white plates, publ. by Reichert Verlag, Wiesbaden, Germany, 2007, \$297.00. This work reviews the history and known examples of carved gems (primarily rings and cameos) from the second through the seventh centuries $A D$, which are far rarer than examples from periods before the decline of the Roman Empire. More than 1,000 gems from different collections are discussed according to genre, theme, material, and place or time of production.

TWO 